\title{
GMR
}

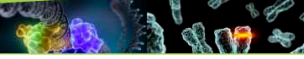

\section{Polymorphisms in the nuclear factor kappa $B$ gene association with recurrent embryo implantation failure}

\author{
L. Luo ${ }^{1}$, D.H. $\mathrm{Li}^{2}$, X.P. $\mathrm{Li}^{2}$, S.C. Zhang', C.F. $\operatorname{Yan}^{1}$, J.F. Wu ${ }^{3}$, Y.H. Qi ${ }^{4}$ and \\ J. Zhao ${ }^{1}$
}

'The Reproductive Medical Center of the Fourth Hospital of Xi'an, Xi'an, Shaanxi, China

${ }^{2}$ Department of Obstetrics and Gynecology, the Fourth Hospital of Xi'an, Xi'an, Shaanxi, China

${ }^{3}$ Department of Obstetrics and Gynecology,

The Second Hospital of Xi' an Jiao Tong University, Xi'an, Shaanxi, China

${ }^{4}$ Department of Ultrasound, the Second Hospital of Xi'an Jiao Tong University, Xi'an, Shaanxi, China

Corresponding author: J. Zhao

E-mail: zhaojingfck@163.com

Genet. Mol. Res. 15 (2): gmr. 15027759

Received December 14, 2015

Accepted January 15, 2016

Published April 27, 2016

DOI http://dx.doi.org/10.4238/gmr.15027759

\begin{abstract}
Despite more than a century of intensive study, the mechanisms of successful pregnancy remain unclear. Recent research suggests that NF- $\mathrm{KB}$ (nuclear factor kappa B) plays an important role in embryo implantation. In the current study, we aimed to identify SNPs that contribute to genetic susceptibility for recurrent implantation failure (RIF). Thus, we examined the potential associations between RIF and ten SNPs (rs28362491, rs3774932, rs1598856, rs230528, rs230521, rs3774956, rs4648055, rs3774964, rs4648068, and rs3774968) of the NF-кB gene. Participants included 209 patients with RIF and 395 controls. Our results revealed that there were statistically significant differences observed in the allelic and genotypic frequencies of the
\end{abstract}


rs28362491 promoter in the NF- $\mathrm{BB}$ gene. The frequency of the del/ del genotype was significantly higher in RIF patients than in healthy controls $(\mathrm{P}=0.004)$. Compared with healthy controls, the RIF patients carried a higher frequency of the rs28362491 del allele $(\mathrm{P}=0.010)$. Furthermore, strong linkage disequilibrium was observed in the three identified haplotype blocks (D' > 0.9). Particularly, in block 1 (rs230528-rs230521), the A-C haplotype occurred significantly more frequently $(P=0.029)$ in subjects with RIF $(P=0.0003)$. In contrast, the A-G haplotype occurred significantly less frequently $(\mathrm{P}=0.008)$ in RIF subjects. These findings support an important role for G-712A polymorphisms of NF- $\mathrm{kB}$ in RIF, and may guide future studies that aim to characterize genetic risk factors for RIF.

Key words: Repeated implantation failure; Nuclear factor kappa B; Single nucleotide polymorphism; SNP

\section{INTRODUCTION}

Recurrent implantation failure (RIF) refers to the failure to achieve a clinical pregnancy after transfer of at least four good-quality embryos from a minimum of three fresh or frozen cycles in a woman under the age of 40 years (Coughlan et al., 2014). Implantation failure is related to either maternal factors or embryonic causes. Maternal factors include uterine anatomic abnormalities, thrombophilia, non-receptive endometrium, and immunological factors. Failures of implantation due to embryonic causes are associated with either genetic abnormalities or other factors intrinsic to the embryo that impair their ability to develop in utero, hatch, and implant (Simon and Laufer, 2012).

Increased incidence of chromosomal translocations, mosaics, inversions, and deletions of genetic material have been reported in patients with RIF (Raziel et al., 2002). Moreover, almost twice as many chromosomal abnormalities were detected in embryos from RIF patients than in embryos of controls (67.4\% versus 36.3\%) (Pehlivan et al., 2003), and significantly more complex chromosomal abnormalities that involve three or more chromosomes were reported in cleaved embryos of RIF patients than in those of controls (Voullaire et al., 2007).

Nuclear factor kappa $\mathrm{B}(\mathrm{NF}-\mathrm{\kappa B})$ proteins are a family of structurally related eukaryotic transcription factors that are persistently active in the pathogenesis of numerous malignancies (Lind et al., 2001; Rueda et al., 2006; Hua et al., 2014) in addition to RIF (Cakmak et al., 2009; Dharmaraj et al., 2010). The NF- $\mathrm{BB}$ family consists of five members in mammals that include the following: NF-KB1 encoding for p50, NF-KB2 encoding for p52, RELA encoding for p65, REL encoding for c-Rel, and RELB encoding for Rel-B. The most common dimer formed by these members is the p65/p50 heterodimer (Lu et al., 2012). The human NF-KB1 gene is located at chromosome region $4 \mathrm{q} 24$. Several researchers have shown a relationship between gastric cancer and polymorphisms in NF-KB1 promoter regions (Inagaki et al., 2009; Tchernitsa et al., 2010; Hua et al., 2014). Therefore, the aim of the current study was to investigate the possible associations between NF-KB1 single nucleotide polymorphisms (SNPs) and susceptibility to RIF. 


\section{MATERIAL AND METHODS}

\section{Subjects}

The study group consisted of 209 women diagnosed with RIF from March 2010 to June 2014 on the basis of the following criteria: all women had $\geq 3$ failed embryo transfers (ET) (ranging from 3-6) with transfers of $\geq 1$ high-quality (grades I and II) fresh or frozen-thawed embryos each; and all patients underwent at least two fresh ET. Embryos were classified as we previously reported as follows: grade $1=$ perfectly symmetrical with no fragmentation; grade 2 = perfectly symmetrical with slight fragmentation $(<20 \%$ fragmentation of the total embryonic volume); grade $3=$ uneven blastomeres with no fragmentation; and grade $4=$ uneven blastomeres with gross fragmentation $(>20 \%$ fragments) (Creus et al., 2003). Embryos of grades 1 or 2 were considered of high quality and were at the 4 -cell or 8 -cell stage on Day 2 or 3 post-fertilization, respectively. For purposes of statistical comparison and to objectively quantify embryo quality, embryos of grades 1-4 were scored 2.5, 2, 1.5 and 1, respectively, as previously reported (Puerto et al., 2003). For the final analysis, the embryo scores per ET were assessed as the mean values of the scores given to each of the transferred embryos. The IVF group $(\mathrm{N}=396)$ consisted of patients undergoing a first IVF-ET cycle before and after each ET, and their success was used to define patients as RIF. This study was approved by the Ethical Committee of the Fourth Hospital of Xi' an (Xi'an, China), and written informed consent was obtained from all participants.

\section{Genotyping}

Whole peripheral blood was obtained from each study participant, and genomic DNA was extracted from blood leukocytes using the E.Z.N.A. Blood DNA Midi Kit (Omega BioTek, Norcross, GA, USA) according to manufacturer protocol. We then searched for SNPs with a minor allele frequency (MAF) $>0.05$ in three different linkage disequilibrium (LD) blocks. Genotyping was carried out for all SNPs using the MassARRAY platform (Sequenom, San Diego, CA, USA). Specifically, SNPs were genotyped using highthroughput matrix-assisted laser desorption ionization time-of-flight (MALDI-TOF) mass spectrometry. Next, the resulting spectra were processed with Typer Analyzer software (Sequenom), and genotype data were generated for each sample. The final genotype call rate of each SNP was $>98 \%$, and the overall genotype call rate was $98.6 \%$, ensuring the reliability of further statistical analysis.

\section{Statistical analysis}

All statistical analyses were carried out using SPSS 16.0 software (SPSS Inc., Chicago, IL, USA). Hardy-Weinberg equilibrium (HWE) was evaluated, and associations between cases and controls for each polymorphism were assessed by Pearson's chi-square tests. A Bonferroni correction was used for multiple tests, wherein the P values were divided by the total number of loci or haplotypes. Pairwise LD statistics ( $D^{\prime}$ and $\mathrm{R}^{2}$ ) and haplotype frequencies were computed using Haploview 4.0 (http://www.broad.mit.edu/mpg/haploview) to construct haplotype blocks. 


\section{RESULTS}

No significant deviations from HWE were found between cases and controls for any of the SNPs identified herein. LD analyses of the patients and controls revealed that seven downstream SNPs were located in a different haplotype block (Fig. 1). Furthermore, LD analysis data showed that rs230528 and rs230521 were located in block 1; rs3774956 and rs4648055 were located in block 2; and that rs4648068, rs3774964, and rs3774968 were located in block 3 . The genotype distribution, allelic frequencies, and haplotypes of the RIF patients and healthy controls are shown in Tables 1-4.

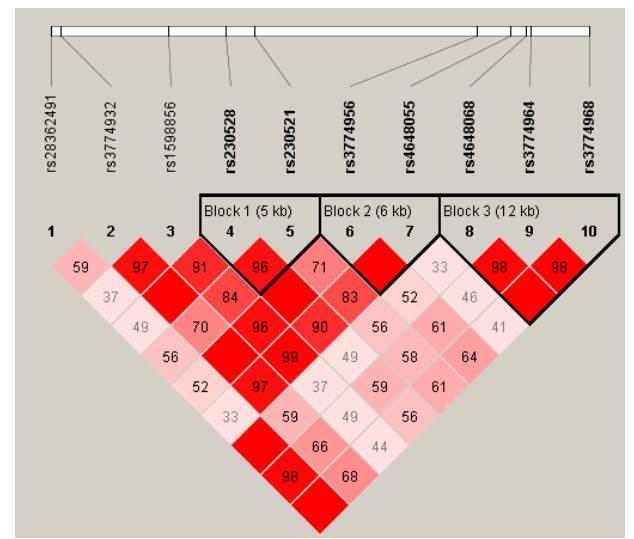

Figure 1. Linkage disequilibrium (LD) plot of the ten single nucleotide polymorphisms (SNPs) in the NFkB gene.

Table 1. Genotypic and allelic frequencies of NF- $\mathrm{\kappa B}$ polymorphisms in the controls and patients with RIF.

\begin{tabular}{|c|c|c|c|c|c|c|c|c|}
\hline \multirow[t]{2}{*}{ Variable } & \multirow[t]{2}{*}{ Group } & \multicolumn{3}{|c|}{ Genotype [N (\%)] } & \multicolumn{2}{|c|}{ Allele [N (\%)] } & \multirow[t]{2}{*}{$\mathrm{P}^{\mathrm{a}}$} & \multirow[t]{2}{*}{$\mathrm{P}^{\mathrm{b}}$} \\
\hline & & ins/ins & ins/del & $\mathrm{del} / \mathrm{del}$ & ins & del & & \\
\hline \multirow[t]{3}{*}{ rs28362491 } & Control & $106(26.84)$ & $214(54.18)$ & $75(18.99)$ & $426(53.92)$ & $364(46.08)$ & \multirow[t]{3}{*}{0.004} & \multirow[t]{3}{*}{0.010} \\
\hline & Case & $49(23.44)$ & $95(45.45)$ & $65(31.10)$ & $193(46.17)$ & $225(53.83)$ & & \\
\hline & & AA & AG & GG & A & G & & \\
\hline \multirow{3}{*}{ rs3774932 } & Control & $151(38.23)$ & $188(47.59)$ & $56(14.18)$ & 490 (62.03) & $300(37.97)$ & \multirow{3}{*}{0.831} & \multirow[t]{3}{*}{0.555} \\
\hline & Case & $76(36.36)$ & $100(47.85)$ & $33(15.79)$ & $252(60.29)$ & $166(39.71)$ & & \\
\hline & & $\mathrm{CC}$ & $\mathrm{CT}$ & TT & $\mathrm{C}$ & $\mathrm{T}$ & & \\
\hline \multirow[t]{3}{*}{ rs1598856 } & Control & $115(29.26)$ & $178(45.29)$ & $100(25.45)$ & $408(51.91)$ & $378(48.09)$ & \multirow[t]{3}{*}{0.293} & \multirow[t]{3}{*}{0.755} \\
\hline & Case & $52(25.00)$ & $108(51.92)$ & $48(23.08)$ & $212(50.96)$ & $204(49.04)$ & & \\
\hline & & $\mathrm{AA}$ & $\mathrm{AC}$ & $\mathrm{CC}$ & A & $\mathrm{C}$ & & \\
\hline \multirow[t]{3}{*}{ rs230528 } & Control & $89(22.53)$ & $189(47.85)$ & $117(29.62)$ & $367(46.46)$ & $423(53.54)$ & \multirow[t]{3}{*}{0.498} & \multirow[t]{3}{*}{0.485} \\
\hline & Case & $47(22.49)$ & $109(52.15)$ & $53(25.36)$ & $203(48.56)$ & $215(51.44)$ & & \\
\hline & & $\mathrm{CC}$ & CG & GG & $\mathrm{C}$ & G & & \\
\hline \multirow[t]{3}{*}{ rs230521 } & Control & $148(37.47)$ & $179(45.32)$ & $68(17.22)$ & $475(60.13)$ & $315(39.87)$ & \multirow[t]{3}{*}{0.001} & \multirow[t]{3}{*}{0.0002} \\
\hline & Case & $106(50.72)$ & $85(40.67)$ & $18(8.61)$ & $297(71.05)$ & $121(28.95)$ & & \\
\hline & & $\mathrm{CC}$ & CT & TT & C & $\mathrm{T}$ & & \\
\hline \multirow[t]{3}{*}{ rs3774956 } & Control & $46(11.65)$ & 177 (44.81) & $172(43.54)$ & $269(34.05)$ & $521(65.95)$ & \multirow[t]{3}{*}{0.993} & \multirow[t]{3}{*}{0.956} \\
\hline & Case & $25(11.96)$ & $93(44.50)$ & $91(43.54)$ & $143(34.21)$ & $275(65.79)$ & & \\
\hline & & AA & $\mathrm{AG}$ & $\mathrm{GG}$ & A & $\mathrm{G}$ & & \\
\hline \multirow[t]{3}{*}{ rs 4648055} & Control & $115(29.11)$ & $178(45.06)$ & $102(25.82)$ & $408(51.65)$ & $382(48.35)$ & \multirow[t]{3}{*}{0.887} & \multirow[t]{3}{*}{0.759} \\
\hline & Case & $57(27.27)$ & $98(46.89)$ & $54(25.84)$ & $212(50.72)$ & $206(49.28)$ & & \\
\hline & & AA & AG & GG & A & G & & \\
\hline \multirow[t]{3}{*}{ rs3774964 } & Control & $112(28.35)$ & $210(53.16)$ & $73(18.48)$ & 434 (54.94) & $356(45.06)$ & \multirow[t]{3}{*}{0.137} & 0.773 \\
\hline & Case & $66(31.58)$ & $94(44.98)$ & $49(23.44)$ & 226 (54.07) & $192(45.93)$ & & \\
\hline & & AA & $\mathrm{AG}$ & GG & A & G & & \\
\hline rs4648068 & Control & $106(26.84)$ & 214 (54.18) & $75(18.99)$ & $426(53.92)$ & 364 (46.08) & 0.004 & 0.010 \\
\hline & Case & $49(23.44)$ & $95(45.45)$ & $65(31.10)$ & $193(46.17)$ & $225(53.82)$ & & \\
\hline & & AA & AG & GG & A & G & & \\
\hline rs3774968 & Control & $100(25.32)$ & 214 (54.18) & $81(20.51)$ & $414(52.41)$ & 376 (47.59) & 0.119 & 0.637 \\
\hline & Case & $65(31.10)$ & $95(45.45)$ & $49(23.44)$ & $225(53.83)$ & $193(46.17)$ & & \\
\hline
\end{tabular}

${ }^{a} \mathrm{P}$ values for genotype frequency differences between RIF patients and controls. ${ }^{\mathrm{b}} \mathrm{P}$ values for allele frequency differences between RIF patients and controls. Alpha values were adjusted by Bonferroni correction and statistically significant results are shown as $\mathrm{P}<0.005$. 
Table 2. NF-кB haplotype in block 1 frequencies and the results of their associations with risk of RIF.

\begin{tabular}{l|c|c|c|c|c|c}
\hline \multirow{2}{*}{ Variable } & \multicolumn{2}{|c|}{ Case (209) } & \multicolumn{2}{c|}{ Control (395) $^{*}$ P value } & \multirow{2}{*}{ OR, 95\%CI } \\
\cline { 2 - 5 } & $\mathrm{N}$ & $\%$ & $\mathrm{~N}$ & $\%$ & & \\
\hline $\mathrm{C}-\mathrm{C}$ & 106 & 50.72 & 208 & 52.66 & 0.650 & $0.925,0.662-1.294$ \\
\hline A-G & 59 & 28.22 & 154 & 38.99 & 0.008 & $0.616,0.428-0.885$ \\
\hline A-C & 42 & 20.10 & 29 & 7.34 & 0.0003 & $2.498,1.500-4.160$ \\
\hline
\end{tabular}

${ }^{\mathrm{a}}$ Based on comparisons of frequency distributions of all haplotypes for the combination of SNPs.

Table 3. NF-kB haplotype in block 2 frequencies and the results of their associations with risk of RIF.

\begin{tabular}{l|c|c|c|c|c|c}
\hline \multirow{2}{*}{ Variable } & \multicolumn{2}{|c|}{ Case (209) } & \multicolumn{2}{c|}{ Control (395) $^{*}$ value $^{\mathrm{a}}$} & \multirow{2}{*}{ OR, 95\%CI } \\
\cline { 2 - 6 } & $\mathrm{N}$ & $\%$ & $\mathrm{~N}$ & $\%$ & & \\
\hline T-A & 105 & 50.24 & 204 & 51.65 & 0.742 & $0.945,0.676-1.322$ \\
\hline C-G & 71 & 33.97 & 135 & 34.18 & 0.959 & $0.991,0.696-1.411$ \\
\hline T-G & 32 & 15.31 & 56 & 14.18 & 0.479 & $0.843,0.524-1.354$ \\
\hline
\end{tabular}

${ }^{\mathrm{a} B a s e d}$ on comparisons of frequency distributions of all haplotypes for the combination of SNPs.

Table 4. NF- $\kappa B$ haplotype in block 3 frequencies and the results of their associations with risk of RIF.

\begin{tabular}{l|c|c|c|c|c|c}
\hline \multirow{2}{*}{ Variable } & \multicolumn{2}{|c|}{ Case (209) } & \multicolumn{2}{|c|}{ Control (395) $^{*}$ value $^{\mathrm{a}}$} & \multirow{2}{*}{ OR, 95\%CI } \\
\cline { 2 - 7 } & $\mathrm{N}$ & $\%$ & $\mathrm{~N}$ & $\%$ & & \\
\hline G-A-A & 111 & 53.11 & 181 & 45.82 & 0.088 & $1.339,0.957-1.874$ \\
\hline A-G-G & 95 & 45.45 & 177 & 44.81 & 0.880 & $1.026,0.733-1.437$ \\
\hline
\end{tabular}

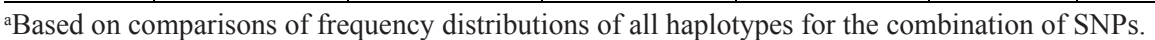

These results demonstrated significant differences in the genotype and allele frequency distributions of rs 28362491 between the RIF patients and healthy controls. Particularly, the frequency of the del/del genotype was significantly higher in RIF patients than that in healthy controls $(\mathrm{P}=0.004)$. Specifically, compared with healthy controls, the RIF patients carried a higher frequency of the rs28362491 del allele $(\mathrm{P}=0.010)$ (Table 1$)$.

The differences in the distributions of genotype frequencies of the haplotypes (block 1) between RIF subjects and healthy controls were significant. Specifically, the A-C (rs230528-rs230521) haplotype occurred significantly more frequently in subjects with RIF than in healthy controls $(\mathrm{P}=0.0003)$. Additionally, the $\mathrm{A}-\mathrm{G}$ haplotypes occurred significantly less frequently in RIF subjects than in healthy con $(\mathrm{P}=0.008)$.

\section{DISCUSSION}

One of the key goals in linkage disequilibrium and association studies is to identify common risk variants in different populations. To determine if common risk variants exist for RIF patients in distinct populations, we compared our results to those of previous studies. The $\mathrm{NF}-\kappa \mathrm{B}$ pathway is a nearly ubiquitous pathway responsible for mediating DNA transcription, and thereby cell function. Additionally, $\mathrm{NF}-\mathrm{\kappa B}$ is a major transcriptional regulator of immune responses, apoptosis, and cell growth control genes. In previous studies, evidence has indicated

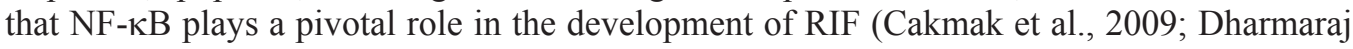
et al., 2010). Importantly, our results herein provide direct evidence that a genetic change in $\mathrm{NF}-\kappa \mathrm{B}$ is linked to RIF in humans. 
Genetic variation contributes to different disease susceptibility. The functional significance of several NF-kB1 SNPs, particularly rs28362491 (-94ins/del ATTG), has been well elucidated (Hogan, 1988). The NF-кB1 -94ins/del ATTG promoter polymorphism is an insertion/deletion of four bases in the promoter region of the NF- $\kappa B$ gene that encodes for the p50 subunit, and the variant allele containing this deletion produces lower transcript levels of the p50 subunit (Karban et al., 2004). The NF- $\mathrm{kB} 1 \mathrm{rs} 28362491$ promoter polymorphism is the only known functional polymorphism in the NF-KB family (van der Heiden et al., 2010; Vogel et al., 2011), and this polymorphism has been shown to be associated with both inflammation and coronary syndrome (Tjønneland et al., 2007). In the current study, we found a significant difference in the genotype distribution of rs28362491 between those with RIF and controls. Specifically, subjects with RIF had a significantly higher frequency of the rs $28362491 \mathrm{del}$ allele than that of controls. Based on these observations, our data indicate that the NF- $\kappa B$ rs28362491 genotype is associated with RIF. To our knowledge, this is the first study to identify a significant association between rs 28362491 in the promoter region of the NF- $\mathrm{KB}$ gene and RIF. However, future in vivo investigations will be required to precisely elucidate the mechanism by which the functional SNPs of NF- $\kappa B$ affect protein function and levels.

In the haplotype analysis, a significant association between NF- $\mathrm{KB}$ gene haplotypes (rs230528-rs230521) and RIF was found. Specifically, the A-C (rs230528-rs230521) haplotype occurred significantly more frequently in subjects with RIF than in controls. These results indicate that people with the A-C haplotype are more prone to RIF. Additionally, the A-G haplotypes occurred significantly less frequently in RIF subjects. These results indicate that patients with the A-G haplotype of the NF-kB gene were less prone to RIF, which further suggests that this haplotype may have protective effects against RIF. However, the functional effects of the different NF- $\kappa B$ haplotypes remain unknown, though they may play an important role in the development of RIF. Evidence from the current study supports the association of NF- $\kappa \mathrm{B}$ polymorphisms and RIF.

In the current study, we found that in a large and homogeneous population, NF- $\mathrm{KB}$ gene polymorphisms (rs28362491) were associated with RIF. These findings encourage future RIF investigations into the functional polymorphisms of NF- $\kappa B$ within in larger sample populations.

\section{Conflicts of interest}

The authors declare no conflicts of interest.

\section{ACKNOWLEDGMENTS}

Research supported by supported by the Shaanxi Province Science and Technology Research and Development Program (\#2014K11-03-09-04), and Function polymorphism in $\mathrm{NF} \kappa \mathrm{B}$ gene associated with the effect of super ovulation drugs in vitro fertilization.

\section{REFERENCES}

Cakmak H, Guzeloglu-Kayisli O, Kayisli UA and Arici A (2009). Immune-endocrine interactions in endometriosis. Front. Biosci. (Elite Ed.) 1: 429-443.

Coughlan C, Ledger W, Wang Q, Liu F, et al. (2014). Recurrent implantation failure: definition and management. Reprod. Biomed. Online 28: 14-38. http://dx.doi.org/10.1016/j.rbmo.2013.08.011 
Creus M, Calafell JM, Cívico S, Fábregues F, et al. (2003). Materno-fetal immunogenetic disparity: the biological basis for in vitro fertilization treatment in patients with unexplained recurrent abortion? Am. J. Reprod. Immunol. 50: 420-426. http://dx.doi.org/10.1034/j.1600-0897.2003.00102.x

Dharmaraj N, Wang P and Carson DD (2010). Cytokine and progesterone receptor interplay in the regulation of MUC1 gene expression. Mol. Endocrinol. 24: 2253-2266. http://dx.doi.org/10.1210/me.2009-0448

Hogan JI (1988). 'The etch-retained metal restoration in hospital clinical use'. Br. Dent. J. 164: 6-7. http://dx.doi. org $/ 10.1038 /$ sj.bdj.4806327

Hua T, Qinsheng W, Xuxia W, Shuguang Z, et al. (2014). Nuclear factor-kappa B1 is associated with gastric cancer in a Chinese population. Medicine (Baltimore) 93: e279. http://dx.doi.org/10.1097/MD.0000000000000279

Inagaki Y, Tang W, Xu HL, Guo Q, et al. (2009). Localization of N-myc downstream-regulated gene 1 in gastric cancer tissue. Dig. Liver Dis. 41: 96-103. http://dx.doi.org/10.1016/j.dld.2008.04.003

Karban AS, Okazaki T, Panhuysen CI, Gallegos T, et al. (2004). Functional annotation of a novel NFKB1 promoter polymorphism that increases risk for ulcerative colitis. Hum. Mol. Genet. 13: 35-45. http://dx.doi.org/10.1093/hmg/ ddh008

Lind DS, Hochwald SN, Malaty J, Rekkas S, et al. (2001). Nuclear factor-kappa B is upregulated in colorectal cancer. Surgery 130: 363-369. http://dx.doi.org/10.1067/msy.2001.116672

Lu R, Gao X, Chen Y, Ni J, et al. (2012). Association of an NFKB1 intron SNP (rs4648068) with gastric cancer patients in the Han Chinese population. BMC Gastroenterol. 12: 1-7. http://dx.doi.org/10.1186/1471-230X-12-87

Pehlivan T, Rubio C, Rodrigo L, Romero J, et al. (2003). Impact of preimplantation genetic diagnosis on IVF outcome in implantation failure patients. Reprod. Biomed. Online 6: 232-237. http://dx.doi.org/10.1016/S1472-6483(10)61715-4

Puerto B, Creus M, Carmona F, Civico S, et al. (2003). Ultrasonography as a predictor of embryo implantation after in vitro fertilization: a controlled study. Fertil. Steril. 79: 1015-1022. http://dx.doi.org/10.1016/S0015-0282(02)04854-9

Raziel A, Friedler S, Schachter M, Kasterstein E, et al. (2002). Increased frequency of female partner chromosomal abnormalities in patients with high-order implantation failure after in vitro fertilization. Fertil. Steril. 78: 515-519. http://dx.doi.org/10.1016/S0015-0282(02)03298-3

Rueda B, Núñez C, López-Nevot MA, Paz Ruiz M, et al. (2006). Functional polymorphism of the NFKB1 gene promoter is not relevant in predisposition to celiac disease. Scand. J. Gastroenterol. 41: 420-423. http://dx.doi. org $/ 10.1080 / 00365520500325929$

Simon A and Laufer N (2012). Assessment and treatment of repeated implantation failure (RIF). J. Assist. Reprod. Genet. 29: 1227-1239. http://dx.doi.org/10.1007/s10815-012-9861-4

Tchernitsa O, Kasajima A, Schäfer R, Kuban RJ, et al. (2010). Systematic evaluation of the miRNA-ome and its downstream effects on mRNA expression identifies gastric cancer progression. J. Pathol. 222: 310-319. http://dx.doi. org/10.1002/path.2759

Tjønneland A, Olsen A, Boll K, Stripp C, et al. (2007). Study design, exposure variables, and socioeconomic determinants of participation in Diet, Cancer and Health: a population-based prospective cohort study of 57,053 men and women in Denmark. Scand. J. Public Health 35: 432-441. http://dx.doi.org/10.1080/14034940601047986

van der Heiden K, Cuhlmann S, Luong A, Zakkar M, et al. (2010). Role of nuclear factor kappaB in cardiovascular health and disease. Clin. Sci. 118: 593-605. http://dx.doi.org/10.1042/CS20090557

Vogel U, Jensen MK, Due KM, Rimm EB, et al. (2011). The NFKB1 ATTG ins/del polymorphism and risk of coronary heart disease in three independent populations. Atherosclerosis 219: 200-204. http://dx.doi.org/10.1016/j. atherosclerosis.2011.06.018

Voullaire L, Collins V, Callaghan T, McBain J, et al. (2007). High incidence of complex chromosome abnormality in cleavage embryos from patients with repeated implantation failure. Fertil. Steril. 87: 1053-1058. http://dx.doi. org/10.1016/j.fertnstert.2006.11.043 